\title{
Management of power transformers reliability by technologies of control on resource characteristics of liquid dielectric
}

\author{
Svetlana Vysogorets ${ }^{1 *}$, Alexandr Nazarychev ${ }^{1}$, Ilia Gorec ${ }^{2}$, Alexey Tadjibaev ${ }^{1}$. \\ ${ }^{1} \mathrm{PEIPK}, \mathrm{SPb}$, Russia \\ ${ }^{2} \mathrm{NRU}$ "HSE SPb", SPb, Russia
}

\begin{abstract}
The relationship between the resource of a power transformer and the resource characteristics of a liquid dielectric is shown. Determined the key quality indicators, which allow to control the resource of the liquid dielectric. For the first time, "The method of experimental determination of the liquid dielectric resource and measures for its restoration" was developed.
\end{abstract}

\section{Introduction}

In power transformers, insulating oil performs a number of functions: dielectric, cooling agent, protective environment, information (diagnostic) environment. For reliable operation in electrical equipment, transformer oils must have the following exploitational characteristics [1]:

- high electrical strength and low electrical conductivity to ensure reliable insulation;

- Sufficient viscosity-temperature properties to provide cooling of the active part of electrical equipment and (or) its start-up at negative temperatures;

- good chemical stability against aging, i.e. ability for a long time not to change its properties in the process of exploitation, ensuring the duration of the service life;

- chemical resistance, i.e. the ability for a long time not to corrupt the solid insulation.

In the course of long-term exploitation in the power transformer, the transformer oil changes its physicochemical and exploitational properties ("ages") and its quality indicators reach limit values. The change in the properties of transformer oils occurs under the influence of several factors. The main process that determines the change in the properties of the oil is its oxidation $[2,3$, 4].

The complex chemical composition of transformer oils explains the ambiguity of their "behaviour" in exploitation, which ultimately causes difficulties in predicting the early stages of oil aging due to the variety of oxidation products being formed. The diversity of the chemical composition of different groups of transformer oils indicates the need to search for methods for evaluating the quality of exploitational oils, taking into account their individual characteristics, working conditions. At the same time, the need to search for methods for recognizing the early aging of insulating oils is dictated by the need for timely corrective (preventive) measures aimed at improving the efficiency of oil regeneration units - thermosyphon and adsorption filters; prevention of the formation of aggressive aging products that cause the destruction of cellulose insulation; reducing the cost of the repair campaign - reducing the complexity of work in the part of transformer cellulose insulation washing from aging products, excluding the costs of oil change; increasing the environmental friendliness of production - reducing the amount of overused oil that is in exploitation of energy companies.

\section{Residual resource of oil and its influence on the resource of electrical equipment}

Along with the most common methods for estimating the degree of transformers aging, such as measurement of the degree of polymerization and furan derivatives, such estimation methods as evaluation of molecular weight distribution with thin-layer (penetrating) chromatography, spectroscopy methods (fluoroscopy, ultraviolet, infrared and near infrared) and polarization methods (the method of recoverable voltage and the method of measuring the tangent of the dielectric loss angle of insulation at various frequencies - parameters depending on the condition of the insulation and do not depend on its geometry). At the same time, none of the existing methods for evaluation the degree of aging of the transformer can provide enough reliable (precise) information. Estimation of the residual resource of the transformer is possible only on the basis of a results analysis of a number of diagnostic methods, accounting the characteristics of the oil and the design features of the transformer. Work in this direction is actively carried out by various researchers [5]. According to the data [6], generator transformers with a voltage of $110 \mathrm{kV}$ (with respiration through a silicagel air dryer) and transformers of higher voltage classes (with film protection) have annual damage due to internal short circuit of less than

Corresponding author: s-151075@yandex.ru 
$0.5 \%$ for 25 years, after 25 years, it increases to $0.75 \%$, and after 35 years to $2.5 \%$, which is including a consequence of decrease in the resource of the transformer grid insulation.

The specified data underline influence of resource characteristics of the transformer isolation on reliability of the equipment. In works $[4,7]$ the efficiency is shown of resource management of a power transformer through the management of the resource of transformer oil filled into it.

Stability - oil stability against oxidation and sludge formation during exploitation. An indicator of the oil quality, determining its resistance to aging factors, is the "antioxidant stability of the oil."

Residual resource of transformer oil - the total exploitational time of transformer oil from the moment of its quality control to the transition to the limiting state, i.e. a condition in which the oil is incapacitated to perform the specified functions, while the restoration of its operable state is impossible and (or) impractical $[4,8]$. Accordingly, a method that allows to qualitatively evaluate the oil resource is the method of measuring "stability against oxidation." One of the approaches widely used in electric power industry for evaluating stability against oxidation is the standardized method GOST 981-75 [9]. The stability of oils, measured according to the specified method [9], is estimated by a set of indicators - acid value of oxidized oil (hereinafter referred to as "AVOO") and sediment formed after oxidation (hereinafter "Sediment"). By measuring the antioxidant stability of the exploitational transformer oil by forced oxidation of the oil sample in the laboratory, we estimate how much the condition of the examined oil, at a given time, is resistant to the influence of key factors that determine the course of oxidation processes, which take place in real conditions. Accordingly, the worse the indicators that determine the stability against oxidation, the greater the proportion of the initial resource of oil is lost. Comparative analysis of the change in the parameters of antioxidant stability before and after the exploitational impact on the oil makes it possible to evaluate the effectiveness of the selected / conducted steps to restore its resource.

Transformer oils are a complex multicomponent system obtained by cleaning distillates of petroleum at a certain temperature. In the process of exploitation, the oils undergo profound changes in the chemical and electrophysical parameters, which are characterized by the general concept of "aging" (oxidation). As a result of the oxidation process, an insoluble sediment (sludge) is released from the oil, acids, water and other aging products appear, incl. aggressive ones. The speed of aging in oil is not constant. At the first stage of exploitation, the speed is small - this is the induction period of oxidation. In the future, as the accumulation of aging products happens, the rate increases, then increases drastically.

Aging mechanisms are applicable for all types of petroleum oils, regardless of the raw materials used for their production, the percentage composition of the components, the methods for cleaning petroleum distillates and other factors. However, the speed of aging processes significantly depends on a number of factors, including temperature, oxygen, metal (oxidation catalyst), etc.

Modeling in laboratory conditions of various methods for restoring the properties of transformer oils, followed by a comparative evaluation of their qualitative changes, is the basis for the first developed "Method for the experimental determination of the liquid dielectric resource and measures for its recovery."

The essence of the method is the comparative oxidation of oil in the VTI appliance under the influence of oxygen at an increased temperature in the presence of a catalyst. The initial sample is subjected to oxidation before processing according to established rules, and then followed by comparison with the accepted standardized values and with the results of oxidation of the oil sample after the exposure to the sample, according to a selected scheme. The results of the oxidation of the oil are characterized by AVOO and Sediment. The method provides experimental evaluation of the transformer exploitational oil resource with the subsequent experimental laboratory determination of the materials volume, nomenclature and the order of works for the regeneration of transformer exploitational oil.

\section{Experimental evaluation of exploitational transformer oil resource}

A qualitative evaluation of the exploitational transformer oil resource is proposed to be conducted by measuring the antioxidant stability according to the GOST 981-75 [9] method using an apparatus for determining the stability of oils against oxidation of APSM-1. The VTI appliance is an integral part of the APSM-1 device, in which oxidation of oils under the influence of oxygen occurs at increased temperatures in the presence of a catalyst. After the process of laboratory forced oxidation of the oil is completed, the measurement of the formed sediment and the acid value of the oxidized oil is conducted, followed by a comprehensive analysis of the results obtained.

In the course of previous research work [4,7], it was established that the threshold values can be taken as the values of AVOO - not more than $0.1 \mathrm{mgKOH} / \mathrm{g}$; Sediment - not more than $0.01 \%$ of the mass. If the threshold values are exceeded, it is recognized that the examinated exploitational transformer oil shows signs of a chemically unstable liquid dielectric, indicating a deterioration in the resource. The presence of the AVOO exceeding the accepted standardized value with the absence of Sediment usually indicates a smaller proportion of the resource expended, in comparison with situations, when there is a presence of Sediment (incl. the excess of the allowable value) during the oil oxidation in the laboratory conditions. Accordingly, according to the results of the tests, two categories of the state of the oil resource are determined: the resource is reduced, and the resource is not reduced.

Examination of the tests results for evaluation the residual resource of a liquid dielectric is carried out in a complex manner, taking into account the results of 
measurements of such quality indicators as acid value, the content of water-soluble acids and alkalis, the tangent of the dielectric loss angle of oil, the content of the antioxidant additive (BHT), the total content of the sludge. These quality parameters are indicative towards aging products formed during oxidation processes in transformer oil $[1,3,4,10]$. Based on the results of a comprehensive review of the measured oil resource and the quality indicators listed above, an algorithm is determined for conducting an experimental laboratory determination of the materials volume, nomenclature and procedure for performing oil regeneration work.

\section{$4 \quad$ Experimental laboratory determination of the materials volume, nomenclature and procedure for performing regeneration of exploitational transformer oil (mineral oil)}

Due to the fact that the chemical composition of transformer oils of different brands is complex and specific, and individual oil conditions exist in each power transformer, the nomenclature of the necessary preventive steps for restoring the oil resource is justifiable to determine by modeling processes in the laboratory (a special laboratory experiment).

To solve the task, the possible and most common combinations of preventive works used in power grid organizations were identified. The impossibility of developing one universal set of measures for the restoration of the oil resource is conditioned by the fact that for a certain degree of oil aging, the effectiveness of its recovery will depend both on the exact set of measures, and on the order of their implementation, the duration of these steps.

Accordingly, the cost of carrying out the work for various sets of measures to restore the resource of the oil will be different. Formulas for calculating costs are listed in Table 1. In this case, the emerging costs $\left(\mathrm{W}_{\mathrm{Mi}}\right)$ will have strict lower and upper limits, which will depend on the proportion of the lost oil resource.
Table 1. Calculation of costs for carrying out preventive works to restore the resource of oil

\begin{tabular}{|c|c|c|}
\hline $\begin{array}{l}\text { Work } \\
\text { option } \\
\text { number }\end{array}$ & $\begin{array}{l}\text { Nomenclature of } \\
\text { works }\end{array}$ & $\begin{array}{l}\text { The formula for } \\
\text { calculating costs } \\
\left(\mathrm{W}_{\mathrm{M}}\right)\end{array}$ \\
\hline $\begin{array}{l}\text { First } \\
\text { option }\end{array}$ & $\begin{array}{l}\text { 1. Replacement of } \\
\text { silicagel in a } \\
\text { thermosyphon } \\
\text { filter. } \\
\text { 2. Oil stabilization } \\
\text { by additive }\end{array}$ & $\begin{array}{l}\mathrm{W}_{\mathrm{M} 1}=\left(\mathrm{C}_{\mathrm{s}} * \mathrm{~m}_{\mathrm{s}}\right) \\
+\left(\mathrm{C}_{\mathrm{BHT}} * \mathrm{~m}_{\mathrm{BHT}}\right) \\
+\mathrm{P}_{1}+\left(\mathrm{P}_{2} * \mathrm{~m}_{\mathrm{c}}\right)\end{array}$ \\
\hline $\begin{array}{l}\text { Second } \\
\text { option }\end{array}$ & $\begin{array}{l}\text { 1. Replacement of } \\
\text { silicagel in a } \\
\text { thermosyphon } \\
\text { filter. } \\
\text { 2. Oil regeneration } \\
\text { by special } \\
\text { installation. } \\
\text { 3. Oil stabilization } \\
\text { by additive }\end{array}$ & $\begin{array}{l}\mathrm{W}_{\mathrm{M} 2}=\left(\mathrm{C}_{\mathrm{s}} * \mathrm{~m}_{\mathrm{s}}\right) \\
+\left(\mathrm{C}_{\mathrm{BHT}} * \mathrm{~m}_{\mathrm{BHT}}\right) \\
+\mathrm{P}_{1}+\left(\mathrm{P}_{3} * \mathrm{~m}_{\mathrm{o} 1}\right)\end{array}$ \\
\hline $\begin{array}{l}\text { Third } \\
\text { Option }\end{array}$ & $\begin{array}{l}\text { 1. Major overhaul } \\
\text { of the } \\
\text { transformer in } \\
\text { the second group } \\
\text { of complexity } \\
\text { (with the } \\
\text { washing of the } \\
\text { active part from } \\
\text { aging products). } \\
\text { 2. Replacement of } \\
\text { exploitational oil } \\
\text { for fresh one }\end{array}$ & $\begin{array}{l}\mathrm{W}_{\mathrm{M} 3}=\mathrm{C}_{\mathrm{OH}}+ \\
\left(\mathrm{m}_{\mathrm{O} 2} * \mathrm{C}_{\mathrm{o}}\right) .\end{array}$ \\
\hline
\end{tabular}

Notation:

$\mathrm{C}_{\mathrm{s}}$ - ruble, the cost of $1 \mathrm{~kg}$ of silicagel.

$\mathrm{m}_{\mathrm{s}}-\mathrm{kg}$, mass of silicagel filled in a thermosyphon (adsorption) filter;

$\mathrm{C}_{\mathrm{BHT}}$ - ruble, the cost of $1 \mathrm{~kg}$ of BHT.

$\mathrm{m}_{\mathrm{BHT}}-\mathrm{kg}$, mass of BHT necessary for input into the tank of a power transformer.

$P_{1}$ - ruble, cost of works on replacement of silicagel in thermosyphon (adsorption) filter (determined in accordance with base prices [11] - repair of thermosiphon filters of II group of complexity depending on the type of filter).

$\mathrm{P}_{2}$ - ruble per 1 ton, the cost of processing transformer oil (determined in accordance with the base prices [11] - oil filling in the transformer №01080301).

$\mathrm{m}_{\mathrm{c}}-\mathrm{tn}$, mass of the filled concentrated solution.

$\mathrm{P}_{3}$ - ruble for 1 ton, the cost of processing transformer oil (determined in accordance with the base prices [11] - regeneration with stabilization of transformer oil №01080701).

$\mathrm{m}_{\mathrm{o} 1}-\mathrm{tn}$, mass of the processed oil.

$\mathrm{S}_{\mathrm{OH}}$ - ruble, the cost of overhaul of a power transformer in Group II of complexity.

$\mathrm{m}_{\mathrm{o} 2}-\mathrm{tn}$, the mass of insulating oil filled into the oil tank of the power transformer.

$\mathrm{C}_{\mathrm{o}}$ - ruble, cost of 1 ton of oil.

A key criterion for evaluation the effectiveness of the oil resource restoration $[4,10,12]$ is the change in the 
antioxidant stability before and after exposure to oil. Effective step to change (restore) the resource characteristics of the oil are all the cases of improvement in two or more times in indicators (AVOO and Sediment), characterizing the antioxidant stabilityn.

\section{Conclusion}

The relationship between the resource of a power transformer and the resource characteristics of a liquid dielectric is shown. Key quality indicators have been identified that allow monitoring the resource of a liquid dielectric.

A "Method for the experimental determination of the liquid dielectric resource and measures for its recovery" is developed. The method provides experimental determination of the transformer exploitational oil resource with the subsequent experimental laboratory determination of the materials volume, nomenclature and the order of works for the regeneration of exploitational transformer oil.

\section{References}

1. Handbook on the repair and maintenance of power transformers. - M.: IPKgossluzhby, 2008. - 852 p.

2. Ivanov V.S. Issues of testing and exploitation of transformer oils / V.S.Ivanov. - M.: BTI ORGRES, 1962. - $116 \mathrm{p}$.

3. Power Transformers: reference book / Ed. by S.D. Lizunova, A.K. Lohanina - M.: Energoizdat, 2004. - 616 p.

4. Vysogorets S.P. Development of the new methods and quality valuation algorithm of $35-110 \mathrm{kV}$ power transformer exploitational oil. Dissertation for the degree of Candidate of Engineering Sciences - SPb., $2012-260 \mathrm{p}$.

5. Lutke H., Hohlein J., Kachler A. J. Transformer ageing research on furanic compounds in insulation oil. CJGRE, 2002, rep. 15-302

6. Vanin B.V., Lvov U.N. and others. Issues of increasing the reliability of block transformers. Electrical stations № 7, 2003.

7.

8. Vysogorets S.P. Forecasting the residual resource of power transformers oil on the basis of analysis of the liquid dielectric quality / S.P.Vysogorets // Scientific and Technical Journal «Safety and Reliability of Power Industry» №1(32)2016 - Moscow, 2016, Pp.50-54.

9. GOST 27.002-89 (CMEA Standard 3519-81) Reliability in engineering. Basic concepts. Terms and definitions / M: Izdatelstvo Standartov, 1990-32p.

10. GOST 981-75 Petroleum oils. Method for determination the stability against oxidation / M: Издательство стандартов, 1992 - 9 р.

11. Brai, I.V. Regeneration of transformer oil / I.V.Brai M.: Publishing House «Chemistry»,1972. -168 p.

12. Base prices for work on the repair of power equipment, adequate to the conditions of functioning of a competitive market and technical re-equipment. // Part 6. Base prices for works on repair of transformers and reactors. - M.: 2003. P.54.

13. Aptov, I.S. Chemical materials in electricity industry / I.S.Aptov, M.V. Homyakov - M.: «Energia», 1969. $280 \mathrm{p}$. 